$\begin{array}{lll}\text { GEOFIZIKA VOL. } 36 \quad 2019 & \end{array}$

DOI: $10.15233 / g f z .2019 .36 .3$

Original scientific paper

\title{
Monitoring geomagnetic information in the territory of Croatia
}

\author{
Mario Brkić \\ Faculty of Geodesy, University of Zagreb, Croatia \\ Received 7 November 2018, in final form 15 April 2019
}

\begin{abstract}
In orientation and navigation using compass, reliable map's marginal information of Earth's magnetic field declination and its annual variation, namely geomagnetic information (GI), is crucial. Monitoring geomagnetic information means observing declination and its annual variation and checking the reliability of the actual GI model. A typical way of monitoring GI across a national territory involves conducting periodic geomagnetic network surveys to assess and update the model. The objective of the paper was to investigate improving the GI model reliability when an earlier model's error was raised to standard accuracy, and repeat station network surveys were not yet completed. A series of processing steps in modelling were revised to preserve the original data reliability. The partial 2008.5, 2009.5 and 2010.5 declination solutions were directly reduced to epoch 2015.0, and then to 2016.0, using the IGRF-12 model. The next step was to use 2016 and 2017 quiet daily declination means to estimate corresponding annual variations at surrounding observatories and repeat stations. Normal declination annual variation models were then built for further reductions to epoch 2017.0, and 2018.0, and for forward extrapolations. The quiet days observatory data were analysed to estimate the effect of the input time series length and linear extrapolated time span on forward extrapolation error. Thus, the reliability decline of the initial GI model slowed down in the sequence of models presented. The final GI2018v2 model, valid for 2018.0-2019.0, proved reliable in comparison to the repeat station declination observations of 2018.
\end{abstract}

Keywords: declination, annual variation of declination, reduction, geomagnetic information model

\section{Introduction}

Earth's magnetic field declination $(D)$ and its annual variation $(A V D)$ as marginal information of official and military maps are referred to "geomagnetic information". Used for orientation of guns or men, and navigation of ships or airplanes, Geomagnetic Information (GI) is outdated the moment it is published on maps or built into geomagnetic models. Knowledge of declination deteriorates over time due to the inherent unpredictability of the Earth's magnetic field (see, 
for example, De Santis et al., 2013). In practice, it is extremely important for the sake of safety to know when and where declination will diverge from required accuracy, such as the standard accuracy of $0.1^{\circ}$, or better, required at military, or the $1^{\circ}$ accuracy required at civilian airports (Brkić et al., 2017). Monitoring the Earth's magnetic field in geomagnetic observatories may provide such information. To investigate it in the territory of Croatia, nearby INTERMAGNET (URL01) observatories were chosen. It has already been found from their historical annual means that declination known within a standard accuracy of $0.1^{\circ}$ may last roughly up to the second year after the last geomagnetic survey (Brkic et al., 2013). Another estimation from the annual $D$ means computed by the IGRF-12 model (the 12th generation of the International Geomagnetic Reference Field Model, see Thébault et al., 2015) at all ten Croatian repeat stations showed that seven years after the last survey the uncertainty of model linear extrapolated declinations reached $0.5^{\circ}$ (Brkić et al., 2017).

The establishment and survey of the Basic Geomagnetic Network of the Republic of Croatia (BGNRC) finished in 2010 (Brkić et al., 2013). Although the reoccupation period for the repeat stations was set at 2 to 5 years, the Croatian Geomagnetic Repeat Stations Network (CGRSN) survey actually resumed in 2018. However, the series of GI models that comprise the Earth's internal magnetic field, excluding prominent local anomalies and time-varying fields, whether man-made or natural, was prepared each year to provide actual GI. The last such model was GI2015v1.2 (Brkić et al., 2018). It relied of necessity on IGRF-12 to accomplish reductions of $D$ to epoch 2015.0, and on $D$ predictions in the period 2015.0-2020.0. This was because IGRF-12 resembled nearby observatories' $D$ annual means over historical time. In addition, IGRF-12 has portrayed $A V D$ well, especially from 2000 onwards; in other words, $A V D$ extracted from IGRF-12 has been appropriate to predict $D$ within or close to standard accuracy. The declared maximum declination uncertainty of GI2015v1.2 was $\leq 7$ ' at BGNRC locations. This was checked at the POKUpsko repeat station during a two-day survey in 2017, the first year of the 2nd Geomagnetic Information Renewal Cycle (Brkić et al., 2018). The reliability of the model was also confirmed at the LON geomagnetic observatory (Lonjsko polje) during instrument comparison before and after the 2017 campaign, see section 2 . However, the differences were due to the GI2015v1.2 model's inability to follow ongoing declination at time scales varying from diurnal to annual, and secular variation, assuming no disturbances.

Monitoring GI2015v1.2 declination also involved comparison with LON observatory declination daily means on quiet (Q) days (URL02) with an average daily geomagnetic activity Ap-index of $\leq 4$ (URL03). This criterion was chosen since quietest days were preferred and the largest Ap of some Q1 day present in examined data was 4 . The comparison indicated the annual and longer term deterioration of the reliability of the modelled declination (Fig. 1). It should be noted that LON 2017 data used at the time of calculation were provisional. However, the situation where the previous year's INTERMAGNET data were not yet definitive was the most common (URL01). Statistics confirmed an in- 


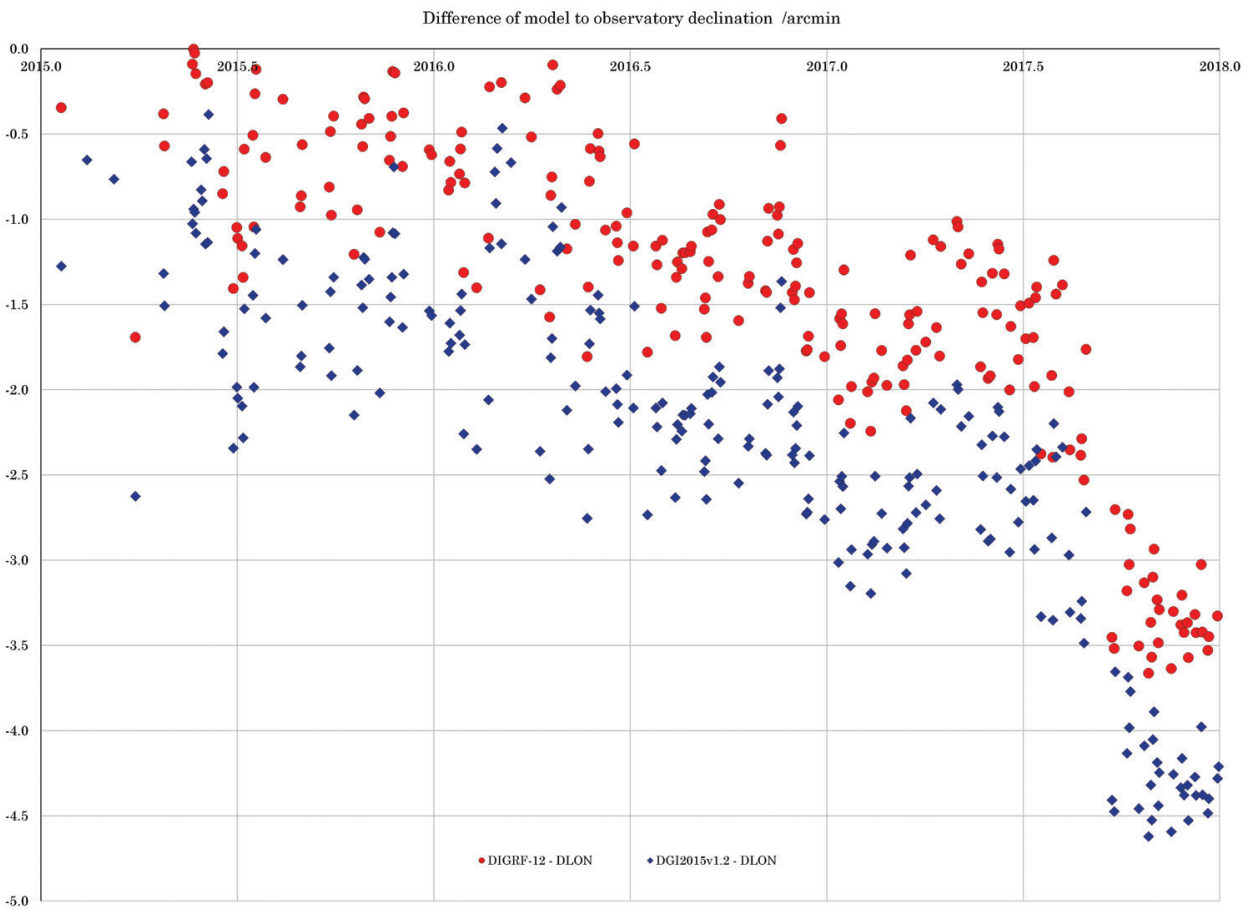

Figure 1. IGRF-12 and GI2015v1.2 model declination error at LON.

crease of root mean square (rms) of GI2015v1.2 to LON declination differences, from 1.5' in 2015, 2.0' in 2016, to 3.3' in 2017. The offset of GI2015v1.2 to IGRF$12 D$ at LON was always approximately 1'. Some deviation of the model in relation to observatory declination was to be expected: standard deviation showed an increase from $0.49^{\prime}$ in 2015 , and $0.53^{\prime}$ in 2016, to $0.89^{\prime}$ in 2017 . According to Fig. 1, we might speculate that the GI2015v1.2 model error would exceed the standard accuracy limit in the following year. Thus, the objective of the paper was to investigate an approach to GI modelling which would preferably keep the error within standard accuracy at BGNRC locations. To accomplish the objective, some steps in GI modelling were revised to foster model accuracy. As an alternative to IGRF-12 in epochs far from 2015.0, the central idea was to use only recent time series of observatory $\mathrm{Q}$ days declination means to model $A V D$ for reductions and extrapolations not too far in the future.

\section{Data, reductions and GI models}

\subsection{GI of the 2015.0 epoch}

In the GI2015v1.2 model, the declinations at BGNRC and surrounding stations refer to epoch 2015.0 (Brkić et al., 2018). These declinations originated 
from the 2008, 2009 and 2010 surveys in southern, western, and northern Croatia, reduced to $2008.5,2009.5$ and 2010.5 epochs respectively, and then to the common epoch solution of 2009.5. The partial solutions of 2008.5, 2009.5 and 2010.5 had a maximum declination scatter of $0.8^{\prime}, 0.7^{\prime}$, and $0.9^{\prime}$ respectively, while the common solution maximum scatter was 2.1' for 98 BGNRC locations (Brkić et al., 2013). In addition, the common or 'start' solution was reduced to 2015.0 by using IGRF-12, assuming the IGRF-12model declination variation and variation observed at BGNRC stations between two epochs were equal (Brkić et al., 2018). The 2015.0 epoch was chosen since it was the starting epoch of the actual generation of the International Reference Geomagnetic Field IGRF12 model, and its annual variation across territory of Croatia was implemented in the GI2015v1.0 model (Brkić et al., 2017). The reduction error to 2015.0 was estimated by using IGRF-12 modelled and observed declination annual means at the Lonjsko polje (LON), Fürstenfeldbruck (FUR), Nagycenk (NCK), Tihany (THY), Grocka (GCK), Panagyurishte (PAG), Duronia (DUR) and Castello Tesino (CTS) observatories, that is, red.err. $=D_{o b s}^{\text {epoch }}+D_{I G R F-12}^{2015.0}-D_{I G R F-12}^{\text {epoch }}-D_{o b s}^{2015.0}$. If the starting epoch of the reduction was 2009.5 (the 'common solution' epoch)

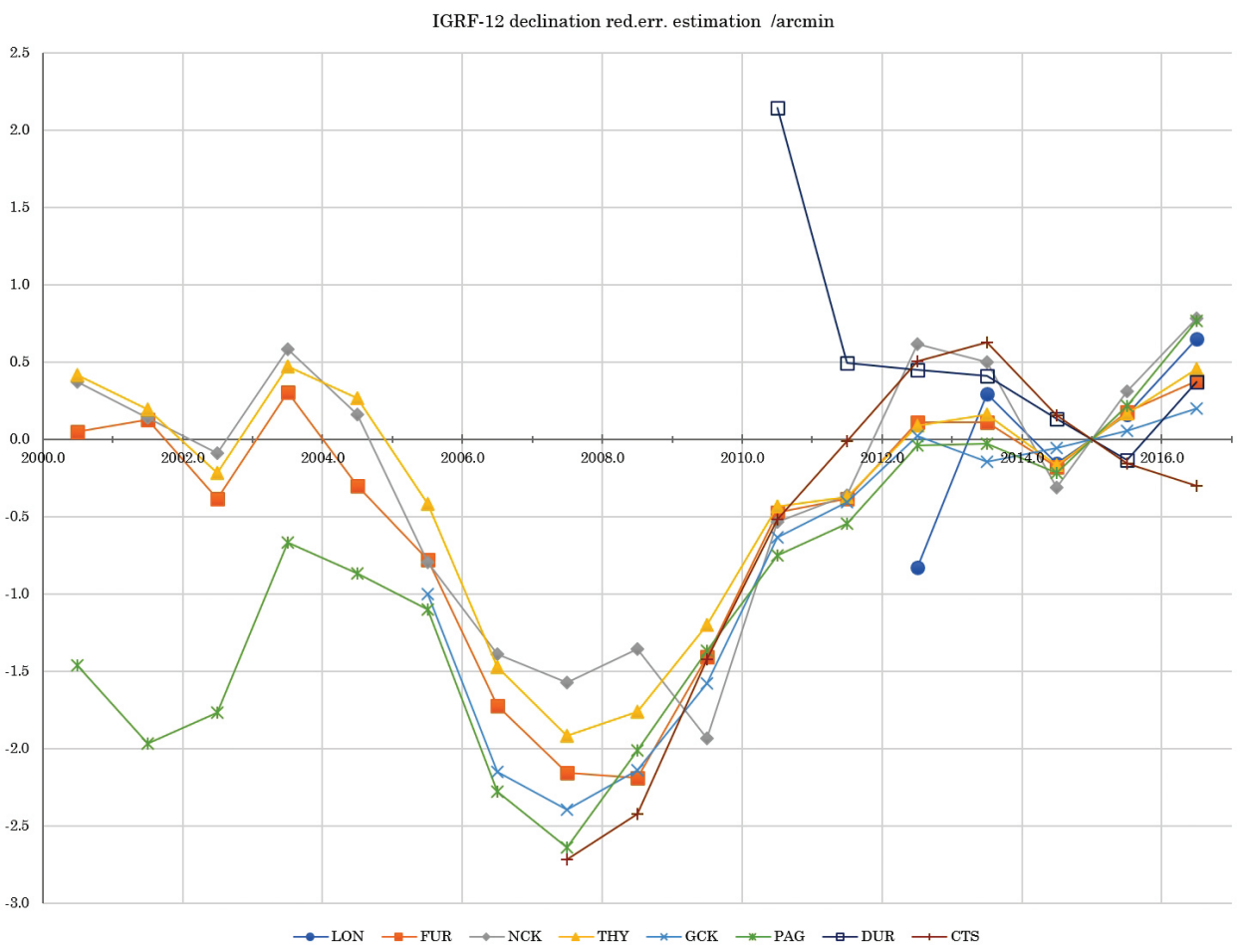

Figure 2. Estimated declination reduction error at nearby observatories. 
then the absolute reduction error might be up to 1.9' (Fig. 2). Thus, after reduction to 2015.0, the maximum error could be up to 4' at BGNRC stations.

However, if the start epochs were 2008.5, 2009.5 and 2010.5, and the maximum absolute reduction errors approximately 2.4', 1.9' and 0.8' (see Fig. 2) at BGNRC sites, then the partial solutions of 2008.5, 2009.5 and 2010.5, after reduction to 2015.0, would contribute a maximum absolute error of approximately 3.2', 2.6', and 1.7' respectively. Therefore, the first change to the GI modelling approach was to apply 'IGRF-12 reductions' to the partial declination solutions of 2008.5, 2009.5 and 2010.5 and reduce them to the 2015.0 epoch. The new model was denoted as GI2015v2.0. The result of the 2008.5, 2009.5 and 2010.5 partial solution reductions gave $D_{\mathrm{GI} 2015 \mathrm{v} 2.0} \geq D_{\mathrm{GI} 2015 \mathrm{v} 1.2}$ within -0.9 ', 0', 1.2', for southern, western and northern Croatia respectively. On the other hand, comparisons of the GI2015v1.2 model with LON $D$ observations in the period 20152017, and the 2017 POKU repeat station absolute measurements, found that the modelled $D$ GI2015v1.2 were always $<D$ as observed at POKU and LON (northern Croatia). Therefore, a slightly enhanced model, pursuant to the partial solutions reductions approach introduced by GI2015v2.0, was anticipated. The later repeat stations survey conducted in 2018 confirmed this expectation. The IGRF-12 reduction to the 2015.0 epoch was also applied to the surrounding declinations, complemented by Italian data (Dominici et al., 2017), the British Geological Survey annual means and magnetic survey data (URL04), and Enhanced Magnetic Model data (URL05); input data cover the area of $37^{\circ}-49^{\circ}$ in latitude and $10^{\circ}-25^{\circ}$ in longitude, similarly to Brkić et al. (2018).

\subsection{GI of the 2016.0, 2017.0 and 2018.0 epochs}

The GI2015v2.0 declinations set was further reduced from the 2015.0 to the 2016.0 epoch, again using IGRF-12 to produce the GI2016 declinations. The earlier figure implied that these reductions would contribute to a declination error of less than 1'. Thus the estimated maximum absolute error of GI2016 declinations for the epoch 2016.0 at BGNRC stations was approximately 3.8'. Similarly, the GI2017 declinations for the epoch 2017.0 were made from GI2016, using IGRF-12. At the time (early in 2018), no observatory means for 2017.0 had been published, so the linear regression of the available Q1 Lonjsko polje (LON) observatory data was used to estimate annual mean. It was found that the reduction error to 2017.0 further contributed around 1', as seen in Fig. 2. Consequently, the GI2017 (IGRF-12 variant) total error at 2017.0 estimated at BGNRC stations was 4.8 .

The models began to decline just before 2016.5 (Fig. 1). Would it have been possible to adjust them by using the another $A V D$ variant, derived from the linear regression of quiet daily declination? At first, for reductions to 2017.0, the Q1 daily $D$ means at observatories were used to estimate their $A V D s$. However, since the input minute provisional or quasi-definitive observatory data in IAGA 
2002 format (URL01) may have been missing or degraded, the $D$ means of quiet $\mathrm{Q}$ days with an index of $\mathrm{Ap} \leq 4$ were adopted to estimate $A V D$. At the time, almost all the 2016-2017 minute data available at INTERMAGNET were definitive and complete, so the Ap $\leq 4 \mathrm{Q}$ days means were used for D 2017.0 and AVD 2016.02017.0 estimation in the case of LON. 'Means' were simply daily means or, rarely, means of minute values of 00-02 plus 22-24 UTC time windows (the later chosen to mimic quiet daily means within $1 \%$ ). The LON $A V D$ difference due to the choice of variant (IGRF-12 vs. linear regression) was around 1 \%yr., while the difference due to the choice of $\mathrm{Q}$ days (all the $\mathrm{Ap} \leq 4$ days vs. only $\mathrm{Q} 1$ days) was negligible. In the case of Conrad (WIC), Nagycenk (NCK), Tihany (THY), Grocka (GCK), Panagjurishte (PAG), and Pedeli (Penteli; PEG) observatories only the Q1 days data of 2016-2017 were used, while in the case of CTS monthly means (Dominici and Cafarella, 2017) were fitted. The Fürstenfeldbruck (FUR) AVD was estimated by using the observatory yearly magnetograms (URL06); the Italian repeat stations (RS) data IT44, IT88, IT94, IT309 and IT302 were compiled from Dominici et al. (2017); Hungarian HU3 and HU9 RS and German DE1, and HRB and DUR were estimated from BGS data (URL04). In the next step, to correct $A V D s$ at stations or observatories where $A V D s$ were declared constant in their models of origin, the average yearly change of AVDs for 20162017 was estimated from more realistic $A V D s$ at observatories in the region of interest. The correction of constant $A V D s$ improved the subsequent normal model figures and residuals.

$A V D$ was usually represented by the geomagnetic normal reference field model via second order coefficients polynomial in latitude and longitude. In contrast to Brkić et al. (2013) and previous papers, all the points used in normal field modelling were from outside Croatia except the LON observatory. Techniques visualised and examined to model $A V D$, were Polynomial Analysis (PA), linear (PA1), quadratic (PA2), intermediate PA bilinear, and Radial Basis Function (RBF). In the future, Spherical Harmonic Analysis methods such as ASHA (see e.g. Vujić et al., 2015) might be also employed. In general, PA showed trends in the field, while RBF depicted anomalous areas clearly. Root mean square and standard deviation of PA residuals were found to be very similar (around $0.2 \%$ yr); however, PA1 normal $A V D$ had the smallest residual at LON, and was suitable for the reduction of all data. The absolute error of reduction from 2016.0 to 2017.0 with PA1 $A V D$ was 0.2 ', and the total error of GI2017 ('PA1 variant') at BGNRC stations for epoch 2017.0 was 4.1'. The model GI2017 'IGRF-12 variant' to 'PA1 variant' differences were around -1.1', which was consistent with Fig. 1. Finally, the selected GI2017 model was the one obtained with PA1 normal $A V D$ for 2016-2017. The model GI2017 ('PA1 variant') was then tested on the LON OBS and POKU RS 2017 absolute observations (Brkić et al., 2018). Comparison of GI2015v1.2 and GI2017(PA1) to POKU gave max. abs. err. 3.5' and 1.9', as well as rms 2.5' and 1.0', respectively. Similarly, comparison of GI2015v1.2 and GI2017(PA1) to LON gave max. abs. err. 4.3' and 2.6', with rms 2.8' and 1.1', 


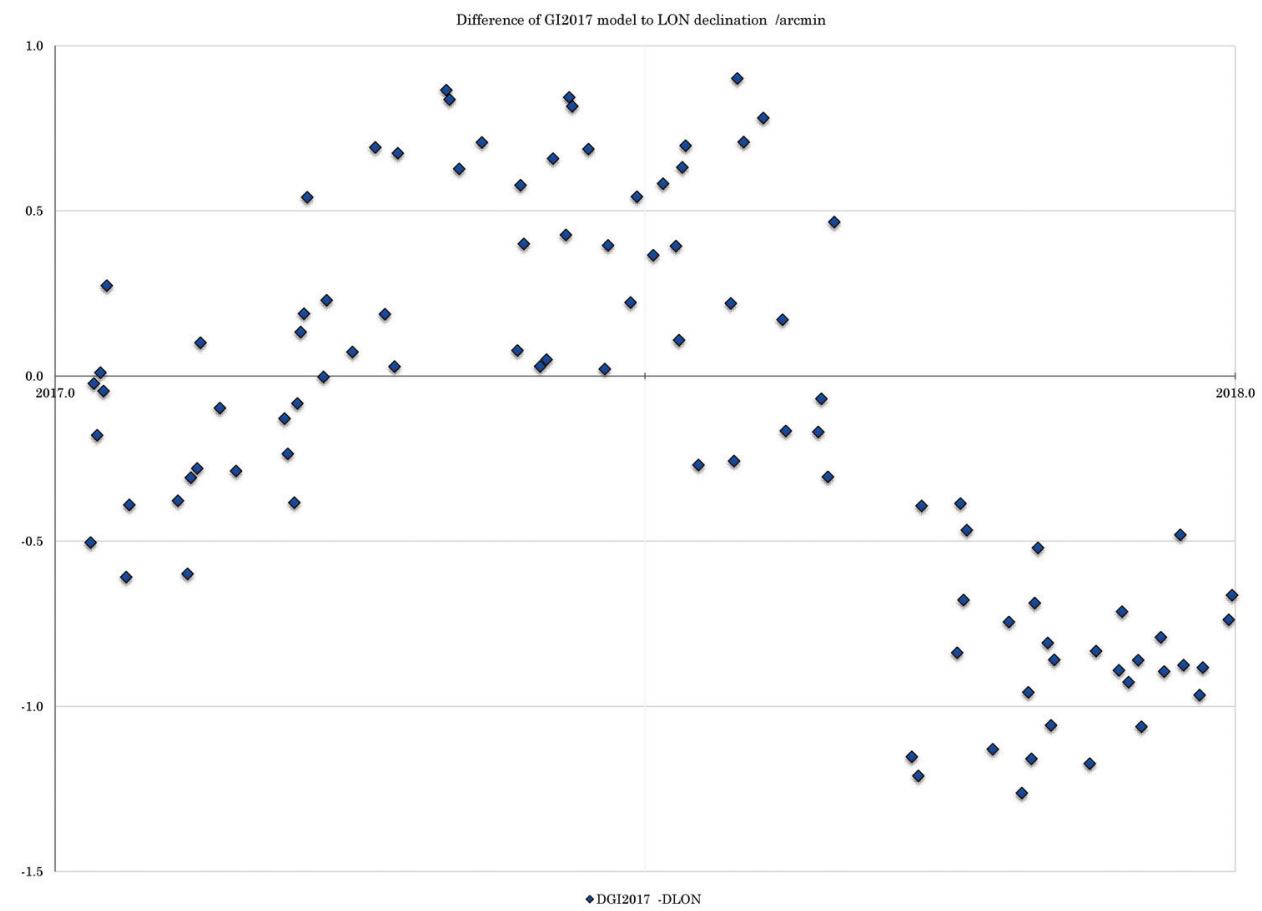

Figure 3. Slowing reliability decline in the GI2017 model.

respectively. The enhancement of the model reliability was due to the new approach confirmed by GI2017 declinations to measurement differences at LON at Ap $\leq 4 \mathrm{Q}$ days of 2017 (compare Fig. 3 and Fig. 1).

The same procedure was repeated to reduce declinations from epoch 2017.0 to 2018.0. GI2018v1 ('IGRF-12 variant') at epoch 2018.0 was obtained from GI2017 ('IGRF-12 variant') using IGRF-12. The maximum absolute reduction error estimated from Q1 LON data was 0.6. The increase in the reduction error in 2017 arose from the fact that the data for that year were not definitive at the time, while IGRF-12 modelling from 2015.0 on was predictive. The total error ('IGRF-12 variant') amounted to 5.4'. The PA variant followed from the PA1 Normal AVD model obtained from 2017-2018 AVDs at the same OBS and RS as the previous year.

This normal annual variation was intended for use in the next period (2018) also but should have been updated when definitive data from stations and observatories were available. $A V D s$ at only five observatories were determined by linear regression of the daily means calculated from provisional or quasi-definitive minute $\mathrm{Ap} \leq 4 \mathrm{Q}$ or $\mathrm{Q} 1$ data, while the annual variations for other stations or observatories were extrapolations plus corrections for constant $A V D$. Tihany data exhibited the strangest behaviour because its $A V D$ in 2017 was 12.5 \%yr., 
and its yearly change of $A V D$ was $>4.4$ ' $y r 2$, so, THY was excluded from PA1 normal modelling. PA1 (and PA2) normal $A V D$ model residuals (differences to $A V D)$ for 2017 showed a slight increase in relation to 2016 residuals, and the rms of differences was 0.5 \%yr., while residual at LON was among the smallest $(0.159$ \% $\mathrm{yr}$.); this rms was taken as the error due to PA1 normal $A V D$ reduction. The GI2018v1 ('PA1 variant') declination total error amounted to 4.5'. The differences between the GI2018v1 'IGRF-12 variant' and 'PA1 variant' differences were all approximately -2.2 ' at BGNRC stations; so it was expected that the decline shown in Fig. 1 would be more or less halted.

\subsection{The actual GI2018v2 model}

At the end of March 2018, INTERMAGNET released definitive LON 2017 data. The rms and abs. max. differences between the 2017 provisional and definitive LON minute $D$ data was considerable, 27" and 49", respectively. Accordingly, the final model GI2018v2 ('PA1 variant') was built using the definitive 2017 LON data. The difference in the 2017 provisional and definitive data was reflected slightly in the 2018.0 declination value (about $0.2^{\prime}$ '), and significantly in the 2017.0-2018.0 AVD (0.5 \% yr) results. The normal PA1 AVD for 2017 was prepared from $A V D s$ at these observatories: Lonjsko polje (LON), Fürstenfeldbruck (FUR), Conrad Observatory (WIC), Nagycenk (NCK), Tihany (THY), Grocka (GCK), Panagjurishte (PAG), Duronia (DUR), Castello Tesino (CTS), Hurbanovo (HRB), Pedeli (PEG), the 'virtual repeat station' L'Aquila (AQU), and DE1, HU3, HU9, and the IT302, IT309, IT94, IT88, and IT44 repeat stations. In the territory monitoring approach that emerged, the importance of the observatories came to light: only LON data was definitive at the time of modelling (May 2018); three OBS produced provisional data, and others were extrapolated from past $D$ and $A V D$ values.

Extrapolated $A V D$ that was found to be constant was further corrected for a change of $A V D$ (it was reasonable to assign the value found for $\mathrm{LON}$ in relation to the previous year). The rms of residuals of PA1 $A V D$ at selected sites was $0.25 \%$ yr., the abs. max. residual was $0.5 \%$ yr., while the residual at LON (the only site inside the area of interest) was $0.005 \%$ yr. Instead of the radial base function used in data gridding to produce the GI2018v2 D and AVD digital models, another technique capable of producing insignificant interpolation residuals at BGNRC stations might be applied. The GI2018v2 ('PA1 variant') model was built from a GI2017 ('PA1 variant') of 2017.0 and the definitive normal PA1 AVD for 2017 at all stations. The maximum difference between GI2018v1 and GI2018v2 ('PA1 variant') declination was 0.5 ' at BGNRC stations. The total error of GI2018v2 ('PA1 variant') declination 2018.0 solution was estimated at between 2.1' to 4.5' at BGNRC stations, while rms 3.3', which was the same as for GI2018v1 ('PA1 variant') declination at epoch 2018.0 (Tab. 1). In comparison, starting GI2015v1 models' declination extrapolated to the epoch 2018.0 estimated rms and max. 
Table 1. Summary of estimated errors at the model's starting epoch.

\begin{tabular}{rccc}
\hline \multicolumn{1}{c}{ Model } & Period of validity & rms /arcmin & max.abs.err. /arcmin \\
\hline GI2015v1.0/v1.1/v1.2 & $2015.0-2020.0$ & 2.8 & 4.0 \\
GI2015v2.0 & $2015.0-2016.0$ & 2.0 & 3.2 \\
GI2016 & $2016.0-2017.0$ & 2.6 & 3.8 \\
GI2017(IGRF-12) & $2017.0-2018.0$ & 3.6 & 4.8 \\
GI2017(PA1) & $2017.0-2018.0$ & 2.8 & 4.1 \\
GI2018v1(IGRF-12) & $2018.0-2019.0$ & 4.2 & 5.4 \\
GI2018v1(PA1) & $2018.0-2019.0$ & 3.3 & 4.5 \\
GI2018v2(PA1) & $2018.0-2019.0$ & 3.3 & 4.5 \\
\hline
\end{tabular}

abs. err. give 5.8' and 7.0', respectively. Actual model GI2018v2 (there is only one, 'PA1 variant') is presented as a map for the 2018.0 epoch in Fig. 4.

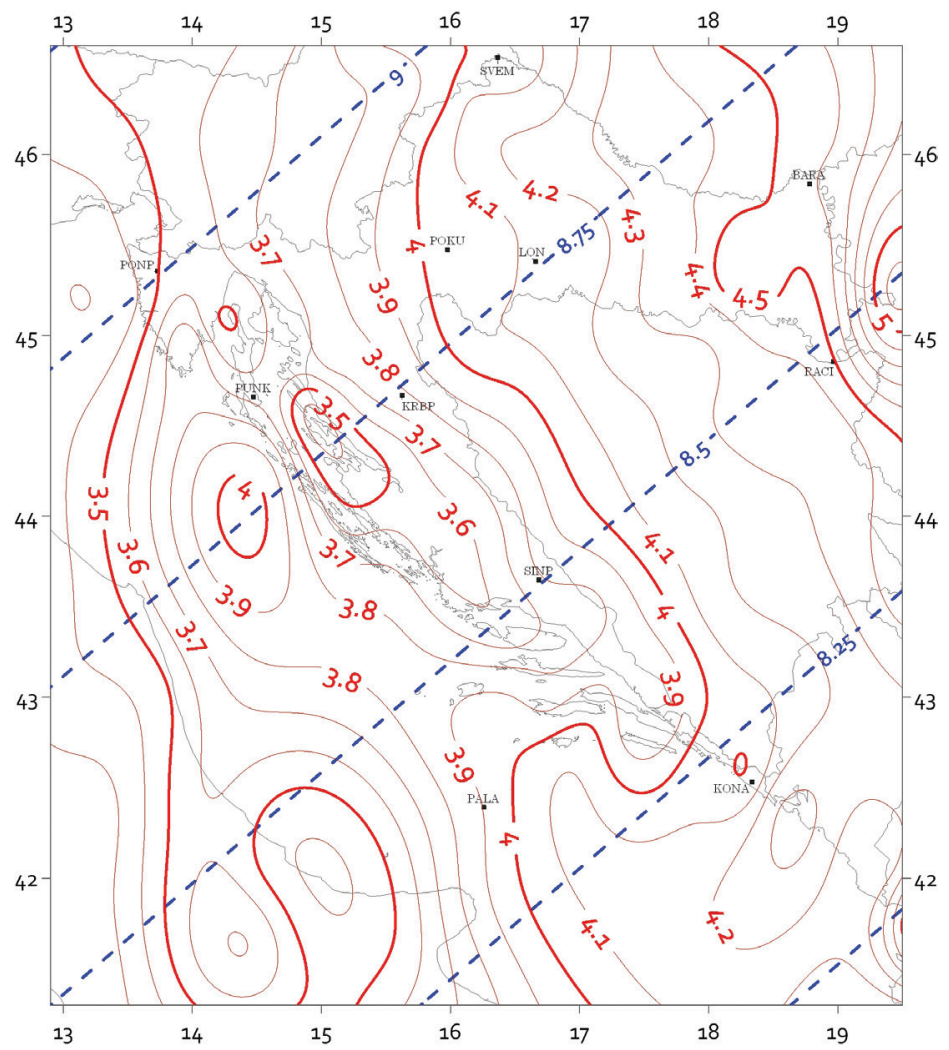

Figure 4. Model GI2018v2 D/ deg (solid line) and AVD / arcmin / yr (dashed) at epoch 2018.0, along with observatory LON, and a new CGRSN of 2018. BGNRC of 2010 was described in (Brkić et al., 2013). 


\subsection{Extrapolation of declination}

In our approach, only the most recent time series of $\mathrm{Q}$ days declinations and near future extrapolations were used, for the following reason. In order to decide the duration of input of recent declination time series (nFIT $=6,12,24$ monthly $\mathrm{Q} 1$ values) in the linear regression, and how far declination (nEXT $=6,12,24$ months) should be extrapolated after regression, the LON daily declination means at Q1 days during 2014-2017 were analysed. The esiduals were formed as the difference between true and predicted declination derived from all possible subsets of time series input into the regression.

The statistics of residuals (Fig. 5) depict nFIT $=12$ and $n E X T=6$ as the preferred choice of fitting and predicting parameters. But both nFIT $=24$ and $\mathrm{nEXT}=6$, and $\mathrm{nFIT}=12$ and $\mathrm{nEXT}=12$ combinations were also considered suitable. These statistics also confirm the maximum and mean of the sum of absolute residuals. All the residuals increase with nEXT. True (not absolute) residual means were well-centred, although they deviated more as nFIT and nEXT increased, and all the extrapolated $D$ were less than the true $D$. According to Fig. 5, the prediction error in 2018 could be as high as 1.5', so the estimated

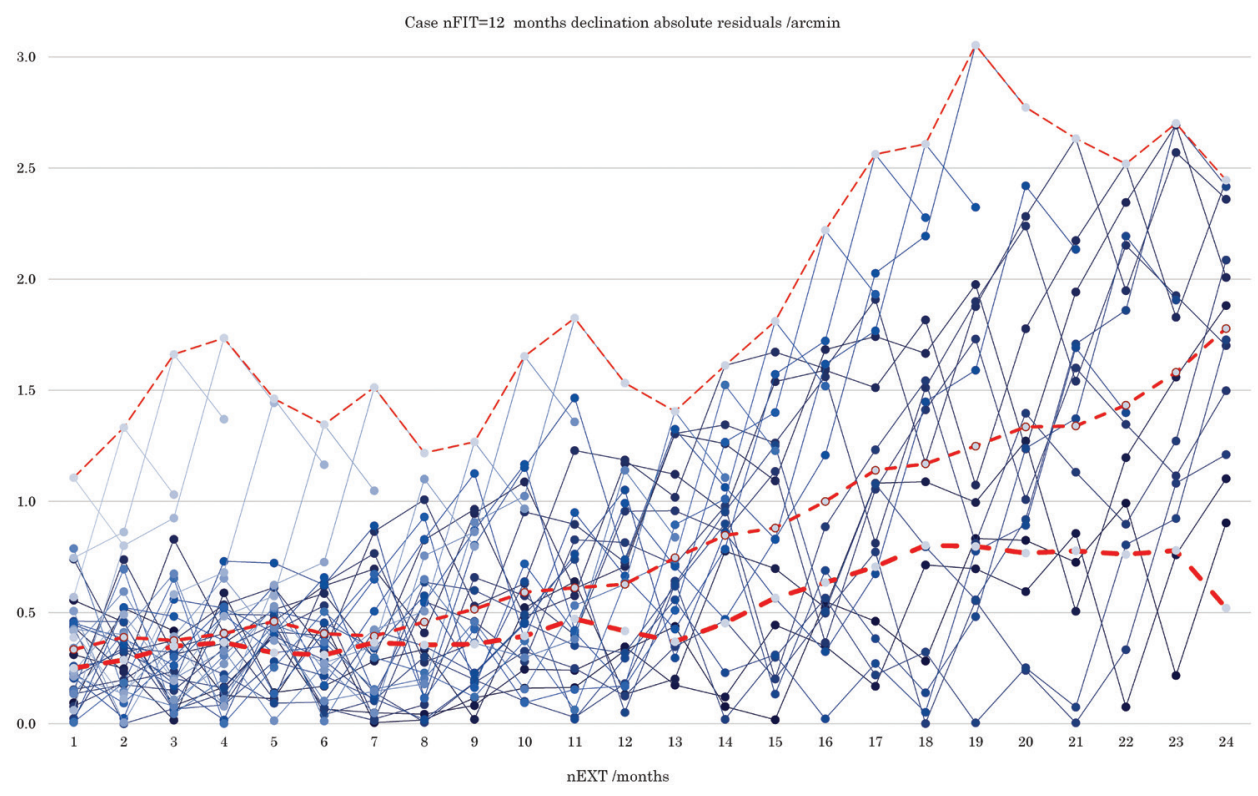

Figure 5. All 35 subsets (blue) with nFIT of 12-month Q1 declination daily means were used to extrapolate up to nEXT of 24 months. The maximum absolute residual was always $>1$ ' and increased irregularly (thin dashed line), while the mean of absolute residuals increased more steadily (dashed line) along with the corresponding standard deviation (thick dashed line). However, some of the last, not fully extrapolated series may exhibit overlarge residuals because of the partial use of non-definitive data. 
GI2018v2 maximum total error in 2018 could be 6'. The reliability of the model should be verified against LON 2018 data, and repeat station observations planned for mid-2018.

\section{Verifying the actual GI2018v2 model}

The 2nd Geomagnetic Information Renewal Cycle was launched in 2017 at the request of the State Geodetic Administration and Ministry of Defence of the Republic of Croatia (Brkić et al., 2018). The goal of the 5-year Cycle (2017-2021) was to provide a reliable geomagnetic information model based on surveys of Croatian Geomagnetic Repeat Stations Network (CGRSN). The repeat stations June/July 2018 survey procedure was better than that of 2017, mainly due to the numerous sets of absolute $D I F$ observations performed as a matter of course, and because the quality control software was upgraded to ensure the observations would suit the reduction.

As the $30 \%$ of the CGRSN of the last survey in 2010 were found destroyed, the new stations had to be setup as close as possible to the old ones (Fig. 4). A new primary POKUpsko repeat station was setup in 2017 (Brkić et al., 2018). The former LOSInj repeat station had been destroyed and contaminated - all the location's points were not found, and large gradients were detected. New over-ground electric cables were also noticed in the vicinity, so a new primary repeat station, PUNta Križ (PUNK), was set up on the island of Cres, on a site that met conditions for repeat station surveys. The most northerly repeat station, MEDJimurje PRM02, was also found to have been contaminated by a new dam, accumulation reservoir and gas plant nearby, so a new primary repeat station SVEti Martin (SVEM) was set up and surveyed.

Since the GI2018v2 model (along with IGRF-12, and WMM2015) does not take diurnal variation into account, while absolute observations more or less do, only the declinations observed close to 04 UTC and 18 UTC were directly com-

Table 2. Repeat station observed to modelled declination absolute max. differences /arcmin.

\begin{tabular}{rccc}
\hline Repeat station & GI2018v2 & IGRF-12 & WMM2015 \\
\hline POKUpsko & 1.0 & 3.7 & 5.9 \\
PALAgruža & 1.9 & 10.5 & 12.1 \\
PUNta Križ & 1.5 & 6.5 & 8.7 \\
SVEti Martin & 1.2 & 7.8 & 5.4 \\
KRBavsko Polje & 2.8 & 1.4 & 2.8 \\
SINjsko Polje & 0.9 & 9.4 & 7.6 \\
KONAvle & 1.2 & 5.9 & 4.6 \\
RACInovci & 1.4 & 3.4 & 5.1 \\
BARAnja & 1.2 & 5.3 & 7.3 \\
PONte Porton & 2.8 & 3.4 & 5.8 \\
\hline
\end{tabular}




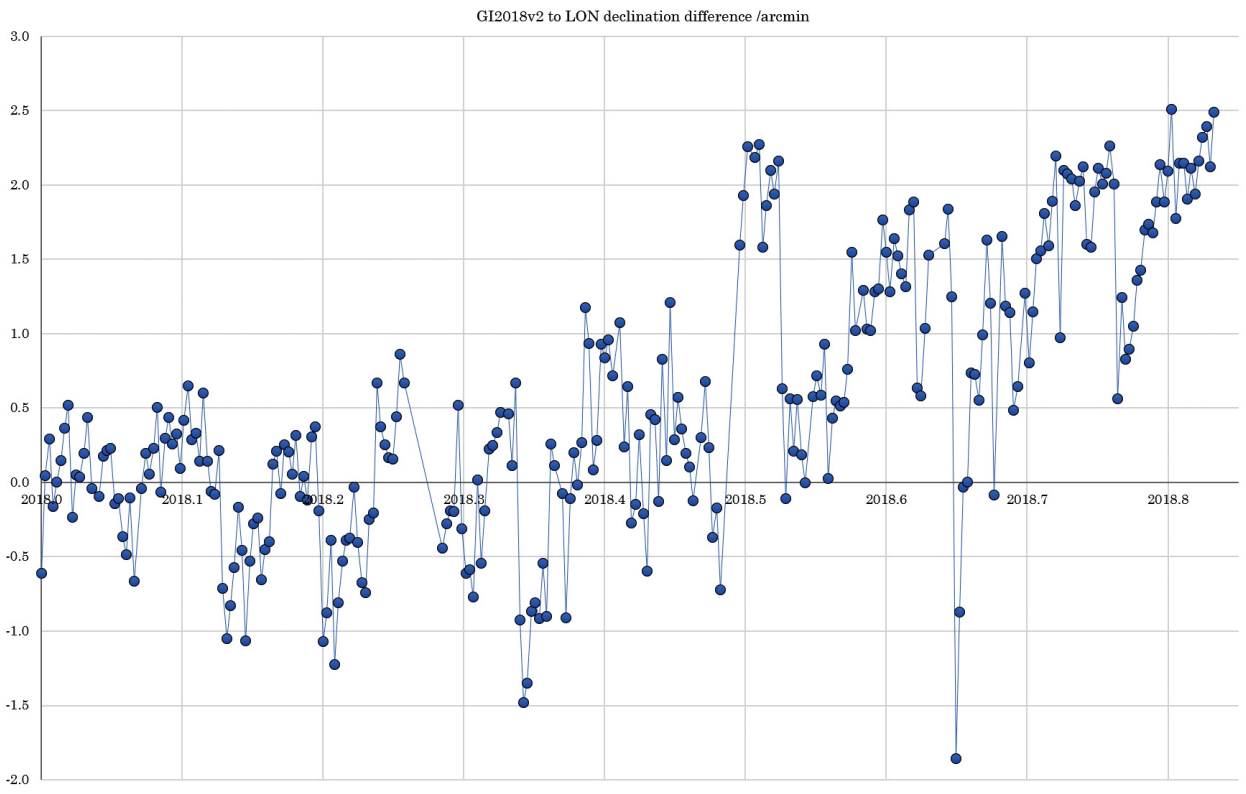

Figure 6. GI2018v2-LON declination differences from quasi-definitive and provisional INTERMAGNET minute data for all days from 1 January to 1 November 2018 (except days with missing data or obvious errors), confirmed the reliability of the actual model to be well within standard accuracy. There was a noticeable decline in the GI2018v2 model starting from about the middle of 2018.

pared to the model (Tab. 2). However, GI2018v2 model differences in all observations were found to be within standard accuracy.

Alongside the new CGRSN, a survey was performed at a new Croatian Geomagnetic Mapping Station Network location at JURovski Brod and the GI2018v2 model declination compared to the observations was found to be $\leq 2.4$ '. The JURB, PUNK and SVEM stations and LON observatory may be regarded as external verifications of the model's reliability, since they were not included in it. Monitoring GI2018v2 model error in the present (Fig. 6) is the key to the renewal of geomagnetic information. The model should be updated in each of the following years by using the available definitive data.

\section{Conclusion}

Continuous monitoring of the actual model error is essential to maintaining the reliability of geomagnetic information. Any discontinuity in surveying, modelling, or monitoring geomagnetic information means errors pile up, presenting a certain security risk. This paper demonstrated an approach to ensuring geomagnetic information model reliability, even eight to ten years after the previous survey reductions. Given the favourable Earth's magnetic field over the Croatian 
territory, we approached data processing to maintain the 1st Geomagnetic Information Renewal Cycle data accuracy. If partial (territorial) declination solutions were established (such as 2008.5, 2009.5 and 2010.5 epochs in our case), it proved beneficial to reduce them one by one to the last starting epoch of IGRF-12 model family (for example, epoch 2015.0). Reduction with the help of IGRF-12 (to 2016.0) showed advantageous. Reductions proceeded using normal annual variations as the first order polynomials in latitude and longitude. Input into declination annual variation normal models was derived by using the linear regression of 2016 and the 2017 quiet daily means at the selected repeat stations and observatories. Although the lack of definitive observatory data from the current and previous year(s) was a major hindrance, the normal models worked well in reductions to 2017.0, and then to 2018.0. The final model achieved (GI2018v2) was not only within standard accuracy, but also closer to the original data reduction error. The paper confirmed that even modest methods and resources could provide trustworthy results. However, for an applied geomagnetic information model update scheme to be enforced, permanent magnetic variometer stations and/or observatory(ies) spanning the national territory would need to be established. A complete Basic Geomagnetic Network survey should only be carried out afterwards. The paper also recommends using the last 12 months of observatories' quiet daily declination means for predicting declination up to the next 6 or 12 months. Accordingly, regular updates of the geomagnetic information model should happen at yearly intervals. Along with fairly regular surveys of the repeat stations network, this approach should guarantee consistently reliable geomagnetic information.

Acknowledgement - We are thankful to Geodetic Administration and Ministry of Defense for supporting the geomagnetic information renewal projects in Croatia. The national institutes that support magnetic observatories Lonjsko polje, Fürstenfeldbruck, Conrad Observatory, Nagycenk, Tihany, Grocka, Panagjurishte, Duronia, Castello Tesino, L’Aquila, Hurbanovo, Pedeli, along with INTERMAGNET are acknowledged for promoting high standards of observatory practice. Istituto Nazionale di Geofisica e Vulcanologia and Istituto Geografico Militare, British Geological Survey, and National Oceanic and Atmospheric Administration are also kindly acknowledged for data and services provided.

\section{References}

Brkić, M., Pavasović, M., Varga, M. and Grgić, M. (2018): II. Cycle of geomagnetic information renewal in the Republic of Croatia - The first results, Cartography and Geoinformation, 17, 4-15.

Brkić, M., Vujić, E., Radović, N., Matika, D. and Bašić, T. (2017): Geomagnetic Information Risk Revisited: A case study of Croatia, in: CODATA-Germany Lecture Notes in Information Sciences Vol. 8, Risk Information Management, Risk Models and Applications, Selected Papers, 2017, edited by Kremers, H. and Susini, A. CODATA-Germany, Berlin, 31-38.

Brkić, M., Vujić, E., Šugar, D., Jungwirth, E., Markovinović, D., Rezo, M., Pavasović, M., Bjelotomić, O., Šljivarić, M., Varga, M. and Poslončec-Petrić, V. (2013): Basic Geomagnetic Network of the Republic of Croatia 2004-2012, with geomagnetic field maps at epoch 2009 (in Croatian). Croatian State Geodetic Administration, Zagreb. 
De Santis, A., Qamili, E. and Cianchini, G. (2013): Repeat-station surveys: implications from chaos and ergodicity of the recent geomagnetic field, Ann. Geophys, 56, 1-7, DOI: 10.4401/ag-5491.

Dominici, G. and Cafarella, L. (2017): Castello Tesino Geomagnetic Observatory Yearbook 2016. Istituto Nazionale di Geofisica e Vulcanologia, Roma.

Dominici, G., Meloni, A., Carroccio, M., Maseroli, R. and Sperti, M. (2017): Italian magnetic network and geomagnetic field maps at year 2015.0. INGV \& IGM.

Thébault, E., Finlay, C. C., Beggan, C. D., Alken, P., Aubert, J., Barrois, O., Bertrand, F., Bondar, T., Boness, A., Brocco, L., Canet, E., Chambodut, A., Chulliat, A., Coïsson, P., F. Civet, F., Du, A., Fournier, A., Fratter, I.,. Gillet, N., B. Hamilton, B., Hamoudi, H., Hulot, G., Jager, T., Korte, M., Kuang, W., Lalanne, X., Langlais, B., Léger, J-M., Lesur, V., Lowes, F. J-. Macmillan, S., Mandea, M., Manoj, C., Maus, S., Olsen, N., Petrov, V., Ridley, V., Rother, M., Sabaka, T. J., Saturnino, D., Schachtschneider, R., Sirol, O., Tangborn, A., Thomson, A., Tøffner-Clausen,, L., Vigneron, P., Wardinski, I. and Zvereva, T. (2015): International geomagnetic reference field: The 12th generation Earth, Earth, Planets and Space, 67:79, 1-19, DOI: 10.1186/s40623-015-0228-9.

Vujić, E., Brkić, M. and Kovács, P. (2015): Regional geomagnetic field model for Croatia at 2009., Acta geophysica, 64, 26-42, DOI: 10.1515/acgeo-2015-0051.

URL01: Intermagnet, http://www.intermagnet.org (last available on 7 November 2018).

URL02: GFZ German Research Centre for Geosciences, https://www.gfz-potsdam.de/, (last available on 7 November 2018).

URL03: SpaceWeatherLive, https://www.spaceweatherlive.com/ (last available on 7 November 2018).

URL04: British Geological Survey, http://www.geomag.bgs.ac.uk/ (last available on 7 November 2018).

URL05: National Centers for Environmental Information, https://www.ngdc.noaa.gov/ (last available on 7 November 2018).

URL06: Department of Earth and Environmental Sciences Munich University https://www. geophysik.uni-muenchen.de/ (7 November 2018).

\section{SAŽETAK}

\section{Praćenje geomagnetske informacije na teritoriju Hrvatske}

\section{Mario Brkić}

U orijentaciji i navigaciji kompasom ključna je pouzdana informacija sa izvanokvirnog sadržaja karata o deklinaciji Zemljina magnetskog polja i njenoj godišnjoj promjeni, geomagnetska informacija (GI). Praćenje geomagnetske informacije podrazumijeva opažanje deklinacije i njene godišnje promjene i provjeru pouzdanosti aktualnog GI modela. Tipičan način praćenja GI nacionalnog teritorija je provedbom periodičnih izmjera geomagnetskih mreža poradi ocjene i ažuriranja modela. U okolnostima kada je pogreška prethodnih GI modela narasla do standardne točnosti, a izmjere sekularne mreže tek trebaju biti dovršene, cilj rada bio je istražiti pristup za poboljšanjem pouzdanosti GI modela. Niz koraka procesiranja u modeliranju revidiran je da bi se očuvala izvorna pouzdanost podataka. Prema tomu su parcijalna rješenja deklinacija za 2008,5, 2009,5 i 2010,5 izravno svedena na epohu 2015,0, te zatim 2016,0, koristeći model IGRF-12. U slijedećem koraku uporabljeni su srednjaci mirne dnevne deklinacije iz 2016., te 2017., za procjene pripadnih godišnjih promjena na okolnim opservatorijima i sekularnim točkama. Onda su normalni modeli godišnje promjene deklinacije izrađeni za daljnje redukcije deklinacija na 2017,0, te 2018,0, kao i za ekstrapolacije naprijed. Opservatorijski podaci mirnih dana analizirani su kako bi se procijenio učinak duljine ulaznog vre- 
menskog niza, te linearno ekstrapoliranog vremenskog raspona, na pogrešku ekstrapolacije naprijed. Stoga se početno slabljenje pouzdanosti deklinacije GI modela usporilo u nizu predstavljenih GI modela. Konačni model GI2018v2, valjan za 2018,0-2019,0 potvrdio je pouzdanost u usporedbi s opažanjima deklinacije na sekularnim točkama u 2018.

Ključne riječi: deklinacija, godišnja promjena deklinacije, redukcija, model geomagnetske informacije

Corresponding author's address: Mario Brkić, Faculty of Geodesy, University of Zagreb, Kačićeva 26, HR-10000 Zagreb, Croatia; tel: +385 14639 243, fax: +385 14828 081; e-mail: mbrkic@geof.hr 